\title{
Anterior urethral valves- a case report Rahman $\mathrm{MM}^{1}$, Rahman $\mathrm{PM}^{2}$, Quddush $\mathrm{AR}^{3}$, Hasan $\mathrm{MJ}^{4}$
}

\begin{abstract}
The case is presented to discuss clinical signs, diagnostic tools and therapeutics of anterior urethral valves, an obstructive anomaly of the urinary system in males. Signs of urinary tract obstruction were identified on pre-natal ultrasound in a male fetus and the diagnosis of anterior urethral valves was made through post-natal evaluation. As an initial treatment, vesicostomy was performed in the patient. Later, the valve was fulgurated using an endoscopic procedure. During the follow-up period the patient presented normal renal function. Anterior urethral valve is a rare form of urethral anomaly that must be ruled out in boys with pre-natal ultrasound indicating infravesical obstruction. Vesicostomy used as an initial treatment rather than transurethral fulguration may prevent potential complications that can occur due to the small size of the neonatal urethra
\end{abstract}

Key Words : Anterior urethral valves, Cystourethrography

CBMJ 2013 July: Vol. 02 No. 02 P: 71-74

\section{Introduction}

Urethral valves are infravesical obstructive congenital anomalies that are more common in boys, and posterior urethral valve (PUV) is the most prevalent. The cases of anterior urethral valves (AUV) are still considered quite rare ${ }^{1}$. The recognition and the original report on anterior urethral valves are attributed to D.I. Williams in $1958^{2}$ and, since then, several cases have been described, both separately and in association with proximal urethral diverticula. ${ }^{3}$ In terms of distribution, these valves are more common in the bulbar urethra (40\%), equally occurring both in the penile urethra and in the penoscrotal junction (30\%). Some cases have been described in the navicular fossa, and mistaken for urethral meatal stenosis. ${ }^{4}$ Its occurrence has also been described in adolescents and adults ${ }^{3,5}$ as well as in the VATER association. ${ }^{6}$

This report describes a case of child with anterior urethral valve, emphasizing its clinical and therapeutic aspects.

\section{Case report}

The child was naturally delivered at 36 weeks of gestation, with an Apgar score of 9/10, weight of $2,850 \mathrm{gm}$, length of $46.5 \mathrm{~cm}$, and amniotic fluid with meconium. The patient had already been submitted to prenatal ultrasonographic examination in the 32nd week of gestation, which clearly showed persistent bladder distension and bilateral hydronephrosis with clinical suspicion of PUV (Figure 1a \& 1b).
After birth, the child presented with dripping urination, with bulging of the penile urethra on urinary straining (Figure 2). The examinations made on the first day of life showed the following: urea $=20 \mathrm{mg} / \mathrm{dL}$; creatinine $=0.7$ $\mathrm{mg} / \mathrm{dL}$. The ultrasonography showed renal parenchyma with preserved thickness and echogenicity, with bilateral hydronephrosis. The bladder presented thick walls with dilation of the distal third of the urethra.

The cystourethrography (CUG) performed on the third day of life showed pronounced urethral dilation with diverticulum, suggesting an anterior urethral valve (Figure 3a, 3b.3c). On the fourth day of life, the child underwent cutaneous vesicostomy, with hospital discharge on the fourth postoperative day. After 18 months, a transurethral fulguration of the AUV with simultaneous closure of the vesicostomy was performed.

\footnotetext{
1. * Dr. Md Masudur Rahman, Associate Prof \& Head Department of Radiology \& Imaging, Community Based Medical College Bangladesh.

2. Dr. Prof. Muzibar Rahman, Professor of Surgery, Dhaka Medical College Hospital.

3. Dr. ASM Ruhul Quddush, Associate Professor, Dept of Pediatrics, Community Based Medical College Hospital Bangladesh

4. Dr. Mahmud Javed Hasan , Assistant Professor, Dept of Nephrology, Community Based Medical College Hospital Bangladesh

* Address of correspondence : E-mail : drmasud64@gmail.com Mobile : 01732398297
} 
During the surgery, urethral stenosis distal to the valve was observed, thus requiring open urethrotomy. The patient presented good postoperative outcome, with normal urinary stream. Later on, reconstructive urethroplasty was carried out. The late postoperative evaluation with micturating cystourethrogram (MCUG) and US revealed normal radiological aspect of the bladder and urethra, and improvement of hydronephrosis, with normal renal function, according to the serum levels of urea and creatinine (urea $=23 \mathrm{mg} / \mathrm{dL}$ and creatinine $=0.8 \mathrm{mg} / \mathrm{dL}$ ).

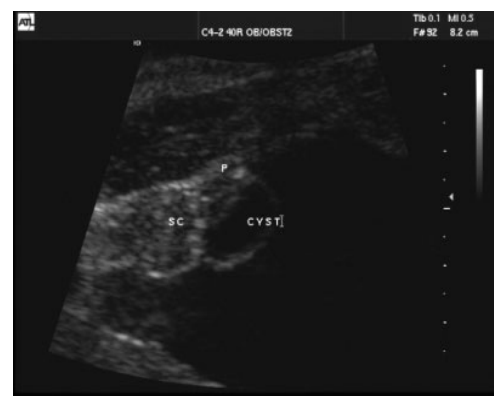

$1 \mathrm{a}$

Figure 1a. Ultrasound image showing a sagittal view of the penis $(P)$, scrotum (SC) and anterior urethral diverticulum (CYST).

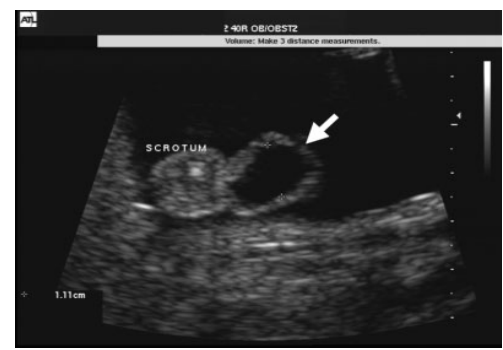

$1 b$

Figure 1b. Ultrasound image showing a transverse view of the scrotum and anterior urethral diverticulum (arrow).

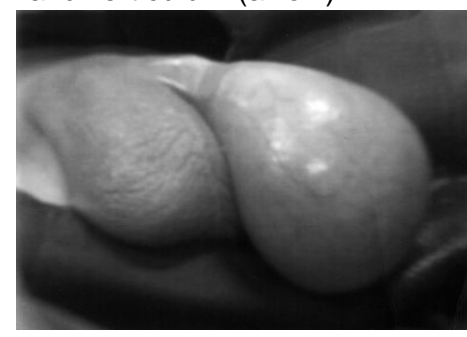

CBMJ 2013 July: Vol. 02 No. 02
Figure 2. Neonatal scrotum and penis with distended anterior urethral diverticulum.

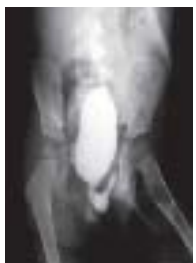

$3 a$

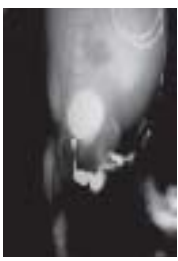

$3 b$

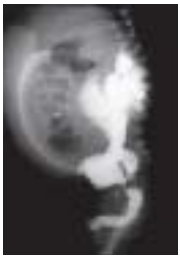

$3 c$
Figure 3a: Dilatation of the anterior urethra proximal to the valve

Figure 3b: Voiding cystourethrogram(VCUG) showing the anterior urethral diverticulum

Figure 3c: VCUG showing urethral dilatation with VUR and hydronephrosis

\section{Discussion}

The routine utilization of ultrasonography in prenatal evaluation has currently become the best-known method for intrauterine diagnosis of several fetal anomalies, especially those related to the urinary tract $^{7}$. On this examination, unilateral or bilateral fetal hydronephrosis, associated or not with oligohydramnios, but followed by persistent bladder distension, is highly suggestive of infravesical obstruction. This hypothesis is reinforced when the simultaneous identification of urethral dilation occurs. In this situation, PUV is the most important anomaly to be ruled out in male patients, since its incidence is estimated at $1 / 30,000$ to $1 / 5,000$ boys ${ }^{8}$. Anterior urethral valve should be considered for differential diagnosis. AUV and urethral diverticula are rare, with a frequency eight times lower than the frequency of posterior urethral valve ${ }^{9}$ Anterior urethral valve, whose etiology is not completely known, may represent an incomplete fusion of a segment of the urethral plate or, an incomplete focal development of the corpus spongiosum with bulging of the urethral mucosa due to ineffective support, which manifests itself as urethral diverticulum. Some authors also consider the possibility that it represents an attempt of urethral duplication in the first 12 to 14 weeks of intrauterine life ${ }^{10}$. In the postnatal period, cases of anterior urethral valve usually occur in the first week of life. The signs and symptoms of urinary obstruction are the most often reported ones; 
with decrease in the strength of the urinary stream or dripping urination in about $40 \%$ of the patients ${ }^{11}$. Serious obstruction concomitantly with hydronephrosis and azotemia may occur in newborns and infants 12,13 . Another common clinical observation in infravesical obstruction through anterior urethral valve is the bulging of the penile urethra caused by the filling and distension of the urethral diverticulum during patient's urinary straining. In general, dripping occurs $^{14}$.

With the obstruction, the concomitant occurrence of bladder distension is common, and the newborn's bladder is easily palpable. Parallel to the analysis of serum urea and creatinine levels, micturating cystourethrography (MCUG) is of paramount importance for the diagnostic confirmation of the location of infravesical obstruction. In this case, the whole urethra has to receive contrast medium for adequate visualization and location of urethral diverticulum associated with PUV ${ }^{15}$. MUCG also allows the identification of vesicoureteral reflux, which may be present in 30\% of these patients. Ultrasonography may suggest the diagnosis of AUV through the visualization of the urethral dilation ${ }^{16}$ and it is useful in the evaluation of the upper urinary tract, since it identifies hydronephrosis of the urethra and the characteristics of the renal parenchyma, especially the presence and intensity of renal dysplasia. Due to the various forms of urinary tract involvement, Firlit et al. $^{9}$ created a classification that contemplates the correlation of the radiological findings of the anterior urethral valve with the clinical and laboratory data. This shows the evolutional aspect of urinary tract involvement, from mild (pronounced hydronephrosis of the urethra) to severe (renal insufficiency) disorders. This influences the attention to be given to Several methods for the treatment of AUV have been proposed, ranging from temporary diversion to primary resection of the urethral diverticulum and valve, in association with necessary procedures for the treatment of possible complications that secondarily affect the upper urinary tract ${ }^{17-19}$. However, most authors agree that transurethral resection of the valve should be made performed when the urethra has a diameter that permits the passage of the resector without causing any trauma. Nowadays, the small diameter of pediatric cystoscopes allows valve resection in the neonatal period, but the procedure should be prescribed according to the general status presented by the patient.

In newborns with altered urinary tract drainage, especially in association with urinary infection, some form of temporary diversion must be considered. In our setting, we have preferably used Blockson cutaneous vesicostomy as temporary urinary diversion in children ${ }^{20}$. This provides fast and effective decompression of the upper urinary tract and prevents the potential complications of resection in small-caliber urethras, such as stenosis or inadequate resection. In addition, it allows the potential reestablishment of renal function in severely affected children.

It is interesting to notice the reduction of the urethral diverticulum, secondary to urinary diversion, without the need of open surgery for adjustment of the urethral lumen in the patients presented here. On the other hand, it is possible to use previous vesicostomy as an entry of the resector for the anteretrograde fulguration of the valve, avoiding the manipulation of the urethra.

\section{Conclusion:}

We recall the importance of anterior urethral valve in children whose prenatal ultrasonography suggests infravesical obstruction, along with the hypothesis of posterior urethral valve. The suspicion of AUV is stronger when urethral dilation is observed during postnatal urinary straining. We also point out that the utilization of vesicostomy as a temporary urinary diversion is recommended in these patients, especially in a long-term follow-up.

\section{References:}

\footnotetext{
1. Wiliams DI, Retik AB. Congenital valves and diverticula of the anterior urethra. $\mathrm{Br} \mathrm{J}$ Urol 969;41:228-34.

2. Kusuda L, Sakti D. Anterior urethral valves. A case report. Scand J Urol Nephrol 1989;23:231

3. Khim A, Harris RD, Raffel J. Anterior urethral valve presenting in an adult male. Urol Radiol 1991;12:196-198. Anterior urethral valves Tucci Jr. S et alii

4. Firlit CF, King LR. Anterior urethral valves in
} children. J Urol 1972;108:972-5. 
5. Punekar SV, Rao NR, Kelkar AR, Gavande $P M$, Prem AR. Anterior urethral valve in an adolescent boy. J Postgrad Med 1995;41:46-

6. Fernbach SK. Urethral abnormalities in neonates with VATER association. Am J

Roentgenol 1991;156:137-140.

7. Mandell J. Diagnosis and management of intrauterine urinary tract disorders. In:

O'Donell B, Koff SA, editores. Pediatric Urology. 3rd ed. Cambridge: Butterworth-

Heunemann; 1997. p. 315-20.

8. Jeffs RD. Posterior urethral valves. In: O'Donnell $B$, Koff SA, editores. Pediatric

Urology. 3rd ed. Cambridge: Butterworth Heinemann; 1977. p. 537-550.

9. Firlit RS, Firlit CF, King LR. Obstructing anterior urethral valves in children. $J$ Urol 978:118:819-21.

10. Small MP, Schoenfeld L. Anterior urethral valves. Urology 1978:11:262-5.

11. Kolte SP, Joharapurkar SR. Anterior urethral valves - a rare cause of urethral obstruction. Indian J Pediatr 2001;68:83-5.

12. Golimbu $M$, Orca $M$, Al-Askari $S$, Morales $P$, Golimbu C. Anterior urethral valves. Urology 978;12:343-6.

13. Aygün C, Güven O, Tekin MI, Peskircioglu $L$ Ozkardes $H$. Anterior urethral valves as a cause of end-stage renal disease. Int $\mathrm{J}$ Urol 2001;8:141-3.
14. Zia-ul-Miraj M. Anterior urethral valves: a rare cause of infravesical obstruction in children. $\mathrm{J}$ Pediatr Surg 2000;35:556-8.

15. Hartig PR, Koos GW, McKinley CR, Meyer JJ. The value of the retrograde urethrogram in the diagnosis of anterior urethral valves. $\mathrm{J}$ Urol 1977;118:309-10.

16. Bates DG, Coley BD. Ultrasound diagnosis of the anterior urethral valve. Pediatr Radiol 2001;31:634-6

17. Rushton HG, Parrot TS, Woodard JR, Walther $M$. The role of vesicostomy in the management of anterior urethral valves in neonates and infants. J Urol 1987;138:107-9.

18. Van Savage JG, Khoury AE, McLorie GA, Bagli DG. An algorithm for the management of anterior urethral valves. J Urol 1997;158:1030-1032.

19. Piro C, Martin JA, Diego M, Chicaiza E, Gozalbez R. Anterior urethral valves. Cir Pediatr 1998;11:64-6.

20. Tucci S Jr, Facincani I, Beduschi MC, Franco $P B$, Martins ACP. Vesicostomia cutânea em crianças. J Pediatr (Rio J) 1997; $\quad$ 73:265-8. 